\title{
Title: Economic evaluation of prescribing conventional and newer oral anticoagulants in older adults
}

\begin{abstract}
Introduction: Anticoagulants refer to a variety of agents that inhibit one or more steps in the coagulation cascade. Generally, clinical conditions that require the prescribing of an oral anticoagulant increase in frequency with age. However, a major challenge of anticoagulation use among older patients is that this group of patients also experience the highest bleeding risk. To date, economic evaluation of prescribing of anticoagulants that includes the novel or newer oral anticoagulants (NOACs) in older adults has not been conducted and is warranted.
\end{abstract}

Areas covered: A review of articles that evaluated the cost of prescribing conventional (e.g. vitamin $\mathrm{K}$ antagonists) and NOACs (e.g. direct thrombin inhibitors and direct factor Xa inhibitors) in older adults.

Expert commentary: While the use of NOACs significantly increases the cost of the initial treatment for thromboembolic disorders, they are still considered cost-effective relative to warfarin since they offer reduced risk of intracranial haemorrhagic events. The optimum anticoagulation with warfarin can be achieved by providing specialised care; clinics managed by pharmacists have been shown to be cost-effective relative to usual care. There are suggestions that genotyping the CYP2C9 and VKORC1 genes is useful for determining more appropriate initial dose and thereby increasing the effectiveness and safety of warfarin.

Keywords: Anticoagulants, economic evaluation, older adults, pharmacogenetic, warfarin

\section{Introduction}

Anticoagulants refer to a variety of agents that inhibit one or more steps in the coagulation cascade [1]. They can be classified according to their mechanism of action, including direct enzymatic inhibition, indirect inhibition by binding to antithrombin and antagonism of vitamin $\mathrm{K}$-dependent factors, by preventing their synthesis in the liver and/or modification of their calcium-binding properties [1]. The list of anticoagulants which are licenced for use include unfractionated heparin, low molecular weight heparins, fondaparinux, vitamin $\mathrm{K}$ antagonists, direct thrombin inhibitors and direct factor Xa inhibitors.

Historically, vitamin $\mathrm{K}$ antagonists were the only anticoagulants widely available for human use. Major concerns with the use of vitamin $\mathrm{K}$ antagonists include the risk of bleeding complications, narrow therapeutic index, variability of dose-response, numerous interactions with other medications, as well as the requirement for frequent monitoring, with associated costs and burdens [2]. Patients receiving vitamin $\mathrm{K}$ antagonists should be aware of 
interactions with food and alcohol. The consumption of large amounts of some specific food (e.g. rich in vitamin $\mathrm{K}$ or cranberries) can lead to over or under coagulation that can increase the risk of thromboembolism or bleeding. In view of these concerns, safer and more convenient anticoagulants have been sought.

The direct thrombin inhibitors and direct factor $\mathrm{Xa}$ inhibitors have been introduced into the market as viable and promising alternatives to warfarin. As their name implies, direct thrombin inhibitors bind to the active site of the thrombin enzyme [3]. The only oral direct thrombin inhibitor available for clinical use is dabigatran etexilate. Another oral agent, ximelagatran, has been withdrawn from the market in 2006 because of concerns surrounding associated hepatotoxicity and cardiovascular events [4]. Direct factor Xa inhibitors inhibit the active site of factor Xa reversibly without the need to bind to antithrombin, hence their name as direct factor Xa inhibitors [5]. Oral direct factor Xa inhibitors available for clinical use include rivaroxaban, apixaban, and edoxaban.

Older adults constitute a patient population who are often viewed as frail and immobile with multiple acute and/or chronic medical disorders and who are often taking multiple medications. The highly prevalent risk factors associated with thromboembolism and the presence of cardiac and thrombotic disorders in older adults necessitate the use of anticoagulant therapy either on a short- or a long-term basis. Some of these conditions also are more prevalent in older adults; non-valvular atrial fibrillation, for instance, increases from $0.5 \%$ between 50 and 59 years to approximately $9 \%$ between 80 and 89 years of age [6]. Similarly, according to the Worcester DVT Study in United States, venous thromboembolism, which encompasses both deep vein thrombosis and/or pulmonary embolism, also increases exponentially with advancing age, rising from an annual incidence of approximately $30 / 100,000$ at age of 40 years to $90 / 100,000$ at age of 60 years and 260/100,000 at age of 80 years [7].

Despite the clear need and benefit of anticoagulants in the older population, there are important concerns pertaining to the appropriateness and safety of these agents. Older adults are inherently more vulnerable to anticoagulant-associated bleeding and may be taking multiple medications that interact and thus mandate extra pharmacovigilance [8]. However, clinical data on older adults is limited, and they are often underrepresented in randomised controlled trials, for reasons such as frailty or renal function [9].

\section{Cost evaluation of prescribing oral anticoagulants}

\subsection{Vitamin $\mathrm{K}$ antagonists}


The usual international normalised target (INR) of 2.0-3.0 which optimises the efficacy and safety of warfarin therapy is difficult to achieve consistently especially among older adult patients due to prevalence of factors such as polypharmacy and comorbidity as discussed in the previous section [10-11]. Even in presence of simple, safe, and accurate warfarin regimen [12], maintaining people on warfarin therapy is a complex process and may lead to incompliance and possible instability of anticoagulation levels [13]. Therefore, warfarin therapy requires regular monitoring of the INR, regardless of age, to ensure its effectiveness and safety. In the average patient, the INR is monitored every 2-4 weeks and such dedicated monitoring comes at a cost.

To date, there is only one systematic review investigating the costs involved in monitoring of the INR during treatment with vitamin $\mathrm{K}$ antagonists [14]. This review included 29 studies from ten countries; the majority of the studies were conducted in the United Kingdom and the United States. As reported in the systematic review, the cost of conducting one INR test ranged from USD 6.19 for point-of-care testing in a primary care clinic, to USD 145.70 for a home visit with laboratory testing. However, the cost of performing one INR test differed with the number of cost categories included in these studies. For example, the study that included the most detailed cost categories, such as staff time, equipment, and consumables, among others, reported higher costs (USD 145.57) than studies that involved only few cost categories (USD 11.75). The costs associated with INR monitoring also differed according to the settings for monitoring. INR monitoring that was performed in specialist hospital clinics reported costs that ranged from USD 11.75 to USD 45.57. On the other hand, for INR monitoring that was conducted in general practice, the costs ranged from USD 24.19 to USD 88.76. Performance of INR monitoring at a practice-based clinic observed a range of costs from USD 6.19 to USD 83.36. The costs reported with home monitoring varied from USD 8.42 to USD 145.57. In addition, the costs also depended on the method of monitoring. For laboratory testing with hospital-based care, the cost of one INR test varied from USD 11.75 to USD 45.57, while those for laboratory testing with general practice-based care varied from USD 24.19 to USD 145.57. For INR monitoring that utilised a computerized decision support system, the reported cost for one INR monitoring ranged from USD 6.19 to USD 83.36 [14]. With the introduction of patient monitoring devices, now INR can be determined by the patients, thus reducing the cost of INR monitoring.

Older patients are at a heightened risk of developing anticoagulant-related bleeding events, where the most fearful events being intracranial haemorrhage and gastrointestinal bleeding. The costs of managing and treating these bleeding events are high [15,16]. In 2010, one study by Kim and colleagues described the hospitalisation costs for bleeding events due to 
warfarin therapy and focused on the older community-dwelling adults [15]. The study was of substantial size, with 2346 subjects over the age of 65 enrolled. It was reported that the mean cost of a warfarin-related hospitalisation was USD 10,819 (standard deviation [SD] = USD 11,536) with a mean length of hospital stay of 7.8 days ( $S D=7.1$ days). When the entire cohort was factored in, warfarin-related bleeding led to an increased cost of hospitalisation of USD 508.30 per warfarin user on average. Ghate et al. assessed health care costs related to warfarin-associated intracranial haemorrhage and gastrointestinal bleeding in 48,069 patients aged 18 years or older with newly diagnosed atrial fibrillation [16]. The mean unadjusted all-cause health care cost per patient within 12 months after initiating warfarin therapy reached USD 41,903 (SD = USD56,654) for patients who experienced at least one event of intracranial haemorrhage. The cost was USD 40,586 (SD = USD 65,164) for patients who experienced at least one event of major gastrointestinal bleeding, and USD 24,347 (SD = USD 56,488) for patients who experienced at least one event of minor gastrointestinal bleeding. After adjustment for patient characteristics, the mean all-cause annual costs totalled USD 42,574 for patients who experienced at least one event of intracranial haemorrhage, USD 36,571 for patients who experienced at least one event of major gastrointestinal bleeding, and USD 22,824 for patients who experienced at least one event of minor gastrointestinal bleeding. Observed higher costs in patients with major gastrointestinal or intracranial bleeding were primarily due to higher utilisation of inpatient service, as manifested by higher all-cause mean inpatient costs, while patients with minor $\mathrm{GI}$ bleeding utilised significantly more outpatient health care services. However, this study did not focus on older adults [16].

\subsection{Novel Oral Anticoagulants}

According to current literature, the NOACs are at least as effective as adjusted dose warfarin therapy (INR of 2.0 to 3.0), when used for FDA-approved indications [17-22]. The clinical trials (Phase III) for NOACs demonstrated that both dabigatran (RE-LY) and apixaban (ARISTOTLE) were more efficacious at preventing stroke in nonvalvular atrial fibrillation than warfarin, while rivaroxaban (ROCKET-AF) was shown to be non-inferior to warfarin [17-19]. At least three meta-analyses have pooled the results from the RE-LY (dabigatran), ARISTOTLE (apixaban), and ROCKET AF (rivaroxaban) trials and reached similar conclusions, where significant reduction of stroke or systemic embolism as well as all-cause mortality were demonstrated as compared to warfarin [20-22]. There are at least two metaanalyses that pooled the results of randomized trials of NOACs for efficacy and bleeding outcomes relative to vitamin $\mathrm{K}$ antagonists among older participants (aged $\geq 75$ years). In the first meta-analysis with ten randomised controlled trials and 25,031 older participants included, it was reported that the risk of major or clinically relevant bleeding was not 
significantly different between NOACs and conventional therapy (warfarin, low-molecularweight heparin, low-molecular-weight heparin followed by vitamin $\mathrm{K}$ antagonists) in older adults [23]. NOACs were also associated with equal or greater efficacy in both preventions of stroke or systemic embolism in atrial fibrillation as well as venous thromboembolism or venous thromboembolism-related death than conventional therapy in older adults. In a separate meta-analysis, which included 11 randomised controlled trials with 31,418 older participants, significant reduction in the risk of major bleeding was observed when compared to vitamin $\mathrm{K}$ antagonist for apixaban, edoxaban $60 \mathrm{mg}$ and $30 \mathrm{mg}$, whereas no significant difference was observed for dabigatran $150 \mathrm{mg}$ and $110 \mathrm{mg}$ as well as rivaroxaban. Each NOAC was also proven to be at least as effective as VKA when used in older patients, both in reduction of the risk of stroke and systemic embolism in atrial fibrillation as well as the risk of recurrent venous thromboembolism [24]. Due to short half-lives of NOACs, a lack of adherence to prescribed NOACs therapy may possibly result in a greater risk for thromboembolic events and decline in therapeutic effect following a missed dose [25]. The decline in therapeutic effect following a single missed dose of the NOACs could put the patients at risk for a thromboembolic event, subsequently leading to added costs to the patient [26]. On the other hand, warfarin takes an average of 4-5 days for therapeutic activity to return to baseline following discontinuation [26]

In a similar manner to warfarin, adverse events like bleeding also contribute significantly to the overall cost of NOACs, especially gastrointestinal bleeding and intracranial haemorrhage. However, all the NOACs demonstrated high relative reduction in the risk of intracranial haemorrhage, which is the bleeding event associated with the highest cost [17-19]. Despite showing important advantage in terms of the rates of intracranial haemorrhage, dabigatran is associated with an increased risk of dyspepsia and gastrointestinal bleeding by as much as $10 \%$, which may increase adverse event-related cost [25].

Although NOACs are reported to not require therapeutic monitoring, there are still some laboratory parameters that must be monitored to ensure safe therapy [27]. Regardless of the type of anticoagulant prescribed, patients should have a complete blood count every 6 months to monitor for bleeding [27]. In addition, due to the hepatic and renal routes of elimination of NOACs, renal and hepatic function monitoring is recommended as clinically indicated which is generally once a year, depending on the agent [27].

\section{Cost-effective approaches in prescribing oral anticoagulants in older adults}

\subsection{Prescribing of NOACs}

A recently published systematic review, which included 54 studies from a vast number of countries, examined the cost-effectiveness of non-vitamin $\mathrm{K}$ antagonists for the prevention of 
stroke in non-valvular atrial fibrillation [28]. The studies generally simulated cohorts of older adult patients, aged from 70 to 75 years, and their cost data were mostly reported in the payer's perspective. As expected for atrial fibrillation treatment, a long-term perspective was adopted for almost all of the included studies. When only the studies with a lifetime perspective were taken into consideration, the mean incremental quality-adjusted life year (QALY) of NOACs was 0.310. An increase in overall health-care costs was observed with the use of NOACs in majority of the studies, but the incremental cost-effectiveness ratio (ICER) was mostly below the reported willingness-to-pay threshold, indicating their costeffectiveness. Additionally, in all the analyses that compared different dabigatran dosages to vitamin $\mathrm{K}$ antagonist, dabigatran $150 \mathrm{mg}$ twice daily and sequential dabigatran dosage approach (150 mg twice daily until the age of 80 and $110 \mathrm{mg}$ twice daily thereafter) showed a better ICER with respect to dabigatran $110 \mathrm{mg}$ twice daily, with dominance reported in majority of the studies. Moreover, among all the studies that compared more than one NOAC to vitamin $\mathrm{K}$ antagonist, apixaban generally performed better than the other NOACs, in which apixaban showed a more favourable ICER with respect to dabigatran $150 \mathrm{mg}$ twice daily, edoxaban, and rivaroxaban, and was found dominant on sequential dabigatran dosage approach, dabigatran $150 \mathrm{mg}$ twice daily and rivaroxaban [28].

In another recently published study (not included in the aforementioned review), the authors analysed the comparative cost-effectiveness of warfarin and NOACs for the prevention of stroke, specifically in older patients with atrial fibrillation [29]. To simulate more closely the real-world settings, the treatment effects were derived from a comprehensive network metaanalysis of oral antithrombotics for the prevention of stroke in atrial fibrillation that included not only data from randomised controlled trials, but also data from observational studies. The authors constructed a life-time Markov model, consisting of 10 health states. The cost categories included treatment and monitoring cost as well as acute and long-term cost of managing clinical events. Local survey and analysis as well as data from published literature were used to correlate the 10 health states and calculate utility values. It was noted in the study that all NOACs, with the exception of dabigatran $110 \mathrm{mg}$ twice daily, were associated with incremental cost-effectiveness ratios of USD 24,476 to USD 41,448 , which were below the recommended cost-effectiveness threshold of USD 49,700 by the World Health Organisation. Threshold analysis reveal that the reported cost-effectiveness was mainly driven by treatment effectiveness of NOACs, in which the reduced risk of ischaemic stroke and intracranial haemorrhage associated with the use of NOACs translated into a lower cost of managing stroke and bleeding events in long term with more QALYs gained, in spite of higher drug acquisition costs of NOACs [29]. 


\subsection{Pharmacist-participated warfarin therapy management}

The cost-effectiveness of pharmacist-participated warfarin therapy management was evaluated in a systematic review of four studies, conducted in the United States and through Asia [30]. All of the included studies compared monitoring services provided by pharmacists or a combination of pharmacists and physicians, compared with usual care. They employed a Markov model with a long-term time horizon for repeated health states that allowed recurrence of health outcomes related to bleeding and embolism, with the different types or levels of bleeding. The efficacy or effectiveness of pharmacist-participated warfarin therapy management was estimated through data derived from trials on the efficacy to control patients' INRs in the therapeutic range or rates of bleeding and thromboembolic events. While there are two studies which reported that pharmacist-participated warfarin therapy management was more expensive than usual care, all included studies concluded that pharmacist-participated warfarin therapy management was either cost-saving or costeffective, which was confirmed by multivariate probabilistic sensitivity analyses. To illustrate, in one of the included studies that focused on older patients at the age of 70 or older with atrial fibrillation who were at high risk of stroke, the authors reported that pharmacistparticipated warfarin therapy management was less costly compared to the usual care with an incremental QALYs gained per person of 0.058 per 10 years, reaching to a conclusion that the pharmacist-participated warfarin therapy management was cost-saving [31].

\subsection{Pharmacogenetic-guided dosing of warfarin}

There are at least three randomised controlled trials of pharmacogenetic-guided dosing of warfarin published to date with the main outcome measure of percentage time spent in therapeutic INR range [32-34]. Although hard clinical outcomes such as bleeding and stroke cannot be reported due to studies being underpowered, percentage time spent in therapeutic INR range is a suitable proxy measure since a $6-10 \%$ improvement in percentage time spent in therapeutic INR range would result in clinically significant improvement in the risk of bleeding and stroke $[35,36]$. One of the trials demonstrated that pharmacogenetic-guided dosing increased the percentage time spent in therapeutic INR range in the initial 12 weeks of therapy by 7.0 percentage points compared to standard dosing [33].

Nevertheless, genotyping would incur additional costs, which therefore necessitates costeffective analysis prior to routine implementation in clinical practice. The evidence to date is not sufficient to conclude the cost-effectiveness of genotype-guided dosing strategy in comparison to normal dosing strategy. This is illustrated in a systematic review by Verhoef et al. which included nine economic studies of pharmacogenetic-guided dosing of warfarin 
derivatives published before the year of 2010 , which were predominantly conducted in the United States [37]. Most of the studies compared pharmacogenetic-guided dosing against standard dosing and reported the number of bleeding events (or adverse events) avoided and QALYs gained as outcome measures. In addition, the majority of the studies evaluated the costs from a healthcare sector perspective and employed a time horizon of 12 months. The cost of CYP2C9 genotyping ranged from US\$67 to US\$350, while the cost of genotyping both VKORC1 and CYP2C9 ranged from US $\$ 200$ to US $\$ 575$. More than half of the included studies observed additional healthcare costs with pharmacogenetic-guided dosing strategy. The costs per adverse event avoided varied from being dominant to US $\$ 170,792$, while the cost per QALY gained varied from US $\$ 171,750$ to US $\$ 347,059$. Due to heterogeneity in the results of the included economic evaluations, no conclusive remarks could be made regarding the cost-effectiveness of this strategy [37].

In a recently published study, which evaluated the cost-effectiveness of the pharmacogenetic-guided dosing of warfarin, the authors constructed a Markov model to compare the incidence of adverse events and QALYs between pharmacogenetic-guided dosing and standard dosing over a lifetime time horizon among patients with atrial fibrillation in United Kingdom and Sweden [38]. This study had less uncertainty around the estimated effectiveness relative to previous studies because this is the only economic study to date that employed the treatment effect from a randomised controlled trial that was appropriately powered, namely, percentage time spent in therapeutic INR range, to populate the constructed Markov model. The authors then extrapolated the treatment effect to the incidence of stroke and bleeding events. Data on costs, utilities and probabilities were obtained from multiple studies within the literature. It was reported in the study that genotype-guided strategy reduced the risk of developing bleeding events by $0.18 \%$ and $0.2 \%$ in the United Kingdom and in Sweden, respectively. A reduction in the risk of thromboembolic events by $0.04 \%$ was noted in both countries. In the United Kingdom, pharmacogenetic-guided strategy caused an increase in lifetime costs of $£ 26$ and QALYs of 0.0039 , resulting in an ICER of $£ 6702$ per QALY gained, which is below the costeffectiveness threshold range of $£ 20000-£ 30000$ per QALY gained. In Sweden, additional costs incurred and QALYs gained were 382 SEK and 0.0015, respectively, with an ICER of 253848 SEK per QALY gained, which is below the cost-effectiveness threshold of 500000 SEK [38].

\section{Expert commentary}

While the use of NOACs significantly increases the cost of pharmacological treatment for thromboembolic disorders, the use of NOACs instead of warfarin is probably associated with a reduction of non-pharmacologic health-care costs, since they offer reduced intracranial 
haemorrhagic events and might improve overall quality of life. It is therefore evident that the increase of the initial economic expenses associated with NOACs must be addressed within a wider perspective. This evaluation should include medical consequences from both the clinical and the economic point of view, which is best achieved with cost-effective analysis. The cost-effectiveness of NOACs proved beneficial in a vast number of countries as reported in the previous section, which demands their wider uptake in clinical practice for patients deemed suitable. Absence of reversal agent for NOACs probably constitutes a barrier to their wider uptake, but reversal agents are being actively developed currently, with idarucizumab has been approved as reversal agent for dabigatran while andexanet alfa proves as reversal agent for anti-factor Xa NOACs [39].

As previously discussed, patients receiving warfarin require close monitoring to ensure optimum anticoagulation and to minimise the risk of bleeding. This can be achieved in anticoagulation clinics that provide specialised care, consistent monitoring, and patient education, especially those managed by pharmacists. Pharmacists in the anticoagulation clinics usually work toward optimisation of warfarin therapy by ordering relevant laboratory tests, monitoring and maintaining target INR, recommending warfarin dose adjustment, reviewing concurrent medications, providing one-to-one patient education and working together with other relevant healthcare professionals $[40,41]$. Indeed, a systematic review and meta-analysis of studies that evaluated the effectiveness of pharmacist-participated warfarin therapy management reported significant reduction in total bleeding events [42]. Several other studies also demonstrated that pharmacist-participated warfarin therapy management led to a significant decrease in warfarin-related hospital admission [43], less frequency of drug interaction [44], a decrease in length of hospital stay [45], significant improvement in patient compliance [46,47], patient knowledge [48], and anticoagulation control [49]. Results from systematic review suggest that pharmacist-participated warfarin therapy management leads to economic benefit, as discussed beforehand.

The dose requirements and the risk of over- or under-anticoagulation with warfarin therapy depend on many clinical and environment factors, including age as well as concurrent illness and medication. Nevertheless, genetic factors, which have been largely overlooked, are responsible for approximately $40 \%$ of the inter-individual variability in response in warfarintreated patients [50,51]. Polymorphisms in the VKORC1 gene, which codes for the pharmacodynamic target enzyme for warfarin, VKORC1, as well as CYP2C9 gene, which codes for the main metabolising enzyme of warfarin, CYP2C9, are associated with variability in dose requirements of warfarin [50,52-54]. Patients with a CYP2C9*2 or *3 allele variant with associated reduction in enzyme activity required lower warfarin dose compared to patients with a wild-type variant [55]. Variants in the VKORC1 allele were also found to be 
playing a role in increased warfarin sensitivity [56]. While the initial dosing of warfarin is based on clinical characteristics currently, there are suggestions that genotyping the CYP2C9 and VKORC1 genes is useful for determining more appropriate initial dose and thereby increasing the effectiveness and safety of warfarin therapy. Therefore, several dosing algorithms have been proposed that incorporated both information on CYP2C9 and VKORC1 genotype as well as clinical factors, and expectation is that patients will achieve and maintain therapeutic INR range if such dosing algorithms are being utilised [51,57,58]. This could decrease the risk of adverse events, including stroke and bleeding, possibly leading to reduced medical costs. Nevertheless, due to heterogeneity in the results of the economic evaluations, no conclusive remarks could be drawn regarding the costeffectiveness of this strategy.

\section{Five-year view}

Evidence from the large and ever-growing body of economic literature about the costeffectiveness of oral anticoagulation therapies has shown that NOACs are cost-effective alternatives to warfarin. Despite increasing evidence on cost-effectiveness of NOACs, the uptake of this new therapeutic class into clinical practice has been slower than expected, especially due to factor related to absence of specific antidotes. Nevertheless, with introduction of idarucizumab as specific reversal agent for dabigatran and possible introduction of andexanet alfa as reversal agent for anti-factor Xa NOACs, the prescribing rate of NOACs is expected to increase. In addition, the entry of the generics of dabigatran following anticipated loss of United States, Japanese, and Canadian patent protection in 2018 will certainly ease the financial pressure of health care system in funding NOACs, which should lead to wider uptake of NOACs in clinical practice in the future.

Nevertheless, the cost-effectiveness of NOACs prescribing relative to pharmacistparticipated warfarin therapy management is unknown. Future economic evaluations should aim to resolve the question, since pharmacists have proved valuable in the management of warfarin therapy. While prescribing rate of NOACs is expected to rise, it would not eliminate the use of warfarin altogether since there are certain patient populations who would benefit from its use, especially those with compromised renal function and therefore contraindicate to the use of NOACs. Pharmacist-participated warfarin therapy management would certainly be helpful to these patient populations who could not take NOACs for any reason in which pharmacist-managed anticoagulation clinic would be expected to continue playing important roles in the coming years.

On the other hand, conclusive evidence on the cost-effectiveness of pharmacogeneticguided dosing of warfarin is still impending, and future economic evaluation of this approach 
is encouraged. It would also be interesting to look at the cost-effectiveness of the NOACs relative to pharmacogenetic-guided dosing of warfarin. With increasing appreciation towards precision medicine, genotype-guided dosing approach for warfarin therapy is promising for years to come.

\section{Key issues}

- Warfarin (vitamin $\mathrm{K}$ antagonist) is the widely available anticoagulant for human use, but it is associated with major concerns such as bleeding complications and the requirement for frequent monitoring.

- Decades of research and development has produced promising alternatives to warfarin, namely, direct thrombin inhibitors (dabigatran) and direct factor Xa inhibitors (apixaban, edoxaban, rivaroxaban).

- Initiation of warfarin therapy requires regular monitoring of the INR regardless of age to ensure its effectiveness and safety. The cost of performing one INR test varied from USD 6.19 to USD 145.70 .

- Each NOAC was also proven to be at least as effective as warfarin when used in older patients, both in reduction of the risk of stroke and systemic embolism in atrial fibrillation as well as the risk of recurrent venous thromboembolism.

- Many studies reported an increase in overall health-care costs with the use of NOACs, but the ICER was mostly below the reported willingness-to-pay threshold, indicating their cost-effectiveness.

- The cost-effectiveness of pharmacist-participated warfarin therapy management was found to be either cost-saving or cost-effective.

- Due to heterogeneity in the results of the economic evaluations, no definitive conclusions on the cost-effectiveness of genotype-guided dosing strategy can be drawn at this time.

- The anticipated loss of United States, Japanese, and Canadian patent protection of dabigatran brand in 2018 should lead to wider uptake of NOACs in clinical practice in the future.

- Due to limited number of studies assessing cost of managing complications and monitoring associated with NOACs, it is currently not possible to recommend which treatment can have more cost-saving effect.

\section{Funding}

This paper was not funded. 


\section{References}

1. Leung LLK. Direct oral anticoagulants and parenteral direct thrombin inhibitors: dosing and adverse effects. Mannucci PM, ed. UpToDate. Waltham, MA: UpToDate Inc. http://www.uptodate.com (Accessed on June 08, 2017.)

2. Ageno W, Gallus AS, Wittkowsky A, Crowther M, Hylek EM, Palareti G. Oral anticoagulant therapy: Antithrombotic Therapy and Prevention of Thrombosis, 9th ed: American College of Chest Physicians Evidence-Based Clinical Practice Guidelines. Chest. 2012 Feb;141(2 Suppl):e44S-e88S.

3. Di Nisio M, Middeldorp S, Büller HR. Direct thrombin inhibitors. N Engl J Med. 2005 Sep 8;353(10):1028-40.

4. Laux V, Perzborn E, Heitmeier S, von Degenfeld G, Dittrich-Wengenroth E, Buchmüller A, Gerdes C, Misselwitz F. Direct inhibitors of coagulation proteins - the end of the heparin and low-molecular-weight heparin era for anticoagulant therapy? Thromb Haemost. 2009 Nov;102(5):892-9.

5. Roehrig S, Straub A, Pohlmann J, Lampe T, Pernerstorfer J, Schlemmer KH, Reinemer $\mathrm{P}$, Perzborn E. Discovery of the novel antithrombotic agent 5-chloro-N-(\{(5S)-2-0xo-3- [4(3-oxomorpholin-4-yl)phenyl]-1,3-oxazolidin-5-yl\}methyl)thiophene- 2-carboxamide (BAY 59-7939): an oral, direct factor Xa inhibitor. J Med Chem. 2005 Sep 22;48(19):5900-8.

6. Kannel WB, Wolf PA, Benjamin EJ, Levy D. Prevalence, incidence, prognosis, and predisposing conditions for atrial fibrillation: population-based estimates. Am J Cardiol. 1998 Oct 16;82(8A):2N-9N.

7. Anderson FA Jr, Wheeler HB, Goldberg RJ, Hosmer DW, Patwardhan NA, Jovanovic B, Forcier A, Dalen JE. A population-based perspective of the hospital incidence and casefatality rates of deep vein thrombosis and pulmonary embolism. The Worcester DVT Study. Arch Intern Med. 1991 May;151(5):933-8.

8. Bajorek B. A review of the safety of anticoagulants in older people using the medicines management pathway: weighing the benefits against the risks. Ther Adv Drug Saf. 2011 Apr;2(2):45-58.

9. Bo M, Grisoglio E, Brunetti E, Falcone $\mathrm{Y}$, Marchionni N. Oral anticoagulant therapy for older patients with atrial fibrillation: a review of current evidence. Eur J Intern Med. 2017 Jun;41:18-27. 
10. Naess IA, Christiansen SC, Romundstad P, Cannegieter SC, Rosendaal FR, Hammerstrøm J. Incidence and mortality of venous thrombosis: a population-based study. J Thromb Haemost. 2007 Apr;5(4):692-9.

11. White HD, Gruber M, Feyzi J, Kaatz S, Tse HF, Husted S, Albers GW. Comparison of outcomes among patients randomized to warfarin therapy according to anticoagulant control: results from SPORTIF III and V. Arch Intern Med. 2007 Feb 12;167(3):239-45.

12. Siguret V, Gouin I, Debray M, Perret-Guillaume C, Boddaert J, Mahé I, Donval V, Seux ML, Pilotaz MR, Gisselbrect M, Verny M, Pautas E. Initiation of warfarin therapy in elderly medical inpatients: A safe and accurate regimen. Am J Med 2005 Feb;118(2):137-42.

13. Costa GL, Ferreira DC, Valacio RA, Vieira Moreira Mda C. Quality of management of oral anticoagulation as assessed by time in therapeutic INR range in elderly and younger patients with low mean years of formal education: a prospective cohort study. Age Ageing. 2011 May;40(3):375-81.

14. Chambers S, Chadda S, Plumb JM. How much does international normalized ratio monitoring cost during oral anticoagulation with a vitamin $\mathrm{K}$ antagonist? A systematic review. Int J Lab Hematol. 2010 Aug 1;32(4):427-42.(** an important systematic review investigating the costs involved in monitoring of the INR during treatment with vitamin $\mathrm{K}$ antagonists)

15. Kim MM, Metlay J, Cohen A, Feldman H, Hennessy S, Kimmel S, Strom B, Doshi JA. Hospitalization costs associated with warfarin-related bleeding events among older community-dwelling adults. Pharmacoepidemiol Drug Saf. 2010 Jul;19(7):731-6.

16. Ghate SR, Biskupiak J, Ye X, Kwong WJ, Brixner DI. All-cause and bleeding-related health care costs in warfarin-treated patients with atrial fibrillation. J Manag Care Pharm. 2011 Nov;17(9):672-84.

17. Connolly SJ, Ezekowitz MD, Yusuf S, Eikelboom J, Oldgren J, Parekh A, Pogue J, Reilly PA, Themeles E, Varrone J, Wang S, Alings M, Xavier D, Zhu J, Diaz R, Lewis BS, Darius H, Diener HC, Joyner CD, Wallentin L; RE-LY Steering Committee and Investigators. Dabigatran versus warfarin in patients with atrial fibrillation. N Engl J Med. 2009 Sep 17;361(12):1139-51.

18. Granger CB, Alexander JH, McMurray JJ, Lopes RD, Hylek EM, Hanna M, Al-Khalidi HR, Ansell J, Atar D, Avezum A, Bahit MC, Diaz R, Easton JD, Ezekowitz JA, Flaker G, Garcia D, Geraldes M, Gersh BJ, Golitsyn S, Goto S, Hermosillo AG, Hohnloser SH, Horowitz J, Mohan P, Jansky P, Lewis BS, Lopez-Sendon JL, Pais P, Parkhomenko A, Verheugt FW, Zhu J, Wallentin L; ARISTOTLE Committees and Investigators. Apixaban versus warfarin in patients with atrial fibrillation. N Engl J Med. 2011 Sep 15;365(11):981-92. 
19. Patel MR, Mahaffey KW, Garg J, Pan G, Singer DE, Hacke W, Breithardt G, Halperin JL, Hankey GJ, Piccini JP, Becker RC, Nessel CC, Paolini JF, Berkowitz SD, Fox KA, Califf $\mathrm{RM}$; ROCKET AF Investigators. Rivaroxaban versus warfarin in nonvalvular atrial fibrillation. N Engl J Med. 2011 Sep 8;365(10):883-91.

20. Dentali F, Riva N, Crowther M, Turpie AG, Lip GY, Ageno W. Efficacy and safety of the novel oral anticoagulants in atrial fibrillation: a systematic review and meta-analysis of the literature. Circulation. 2012 Nov 13;126(20):2381-91.

21. Adam SS, McDuffie JR, Ortel TL, Williams JW Jr. Comparative effectiveness of warfarin and new oral anticoagulants for the management of atrial fibrillation and venous thromboembolism: a systematic review. Ann Intern Med. 2012 Dec 4;157(11):796-807.

22. Ntaios G, Papavasileiou V, Diener HC, Makaritsis K, Michel P. Nonvitamin-K-antagonist oral anticoagulants in patients with atrial fibrillation and previous stroke or transient ischemic attack: a systematic review and meta-analysis of randomized controlled trials. Stroke. 2012 Dec;43(12):3298-304.

23. Sharma M, Cornelius VR, Patel JP, Davies JG, Molokhia M. Efficacy and harms of direct oral anticoagulants in the elderly for stroke prevention in atrial fibrillation and secondary prevention of venous thromboembolism: systematic review and meta-analysis. Circulation. 2015 Jul 21;132(3):194-204.

24. Sardar P, Chatterjee S, Chaudhari S, Lip GY. New oral anticoagulants in elderly adults: evidence from a meta-analysis of randomized trials. J Am Geriatr Soc. 2014 May;62(5):857-64. (** an important meta-analysis on new oral anticoagulants in elderly adults)

25. Weitz JI, Gross PL. New oral anticoagulants: which one should my patient use? Hematology Am Soc Hematol Educ Program. 2012;2012:536-40.

26. Hirsh J, Fuster V, Ansell J, Halperin JL; American Heart Association; American College of Cardiology Foundation. American Heart Association/American College of Cardiology Foundation guide to warfarin therapy. Circulation. 2003 Apr 1;107(12):1692-711.

27. Crouse B, Quigley S. New oral anticoagulants: an economic analysis. Available at https://lecom.edu/new-oral-anticoagulants-an-economic-analysis/ (Accessed on June 08, 2017.)

28. Liberato NL, Marchetti M. Cost-effectiveness of non-vitamin $K$ antagonist oral anticoagulants for stroke prevention in non-valvular atrial fibrillation: a systematic and qualitative review. Expert Rev Pharmacoecon Outcomes Res. 2016;16(2):221-35. (** a significant systematic review on cost-effectiveness of non-vitamin $K$ antagonists for the prevention of stroke in non-valvular atrial fibrillation)

29. Zhao YJ, Lin L, Zhou HJ, Tan KT, Chew AP, Foo CG, Oh CTD, Lim BP, Lim WS. Costeffectiveness modelling of novel oral anticoagulants incorporating real-world elderly 
patients with atrial fibrillation. Int J Cardiol. 2016;220:794-801. (* a significant comparative study on cost-effectiveness of warfarin and NOACs for the prevention of stroke, specifically in older patients with atrial fibrillation)

30. Babar Z. Economic evaluation of pharmacy services. 1st ed. Cambridge, MA: Academic Press; 2016.

31. Sullivan PW, Arant TW, Ellis SL, Ulrich H. The cost effectiveness of anticoagulation management services for patients with atrial fibrillation and at high risk of stroke in the US. Pharmacoeconomics. 2006;24(10):1021-33.

32. Verhoef TI, Ragia G, de Boer A, Barallon R, Kolovou G, Kolovou V, Konstantinides S, Le Cessie S, Maltezos E, van der Meer FJ, Redekop WK, Remkes M, Rosendaal FR, van Schie RM, Tavridou A, Tziakas D, Wadelius M, Manolopoulos VG, Maitland-van der Zee $\mathrm{AH}$; EU-PACT Group. A randomized trial of genotype-guided dosing of acenocoumarol and phenprocoumon. N Engl J Med. 2013 Dec 12;369(24):2304-12.

33. Pirmohamed M, Burnside G, Eriksson N, Jorgensen AL, Toh CH, Nicholson T, Kesteven P, Christersson C, Wahlström B, Stafberg C, Zhang JE, Leathart JB, Kohnke $H$, Maitland-van der Zee AH, Williamson PR, Daly AK, Avery P, Kamali F, Wadelius M; EUPACT Group. A randomized trial of genotype-guided dosing of warfarin. N Engl J Med. 2013 Dec 12;369(24):2294-303.

34. Kimmel SE, French B, Kasner SE, Johnson JA, Anderson JL, Gage BF, Rosenberg YD, Eby CS, Madigan RA, McBane RB, Abdel-Rahman SZ, Stevens SM, Yale S, Mohler ER 3rd, Fang MC, Shah V, Horenstein RB, Limdi NA, Muldowney JA 3rd, Gujral J, Delafontaine P, Desnick RJ, Ortel TL, Billett HH, Pendleton RC, Geller NL, Halperin JL, Goldhaber SZ, Caldwell MD, Califf RM, Ellenberg JH; COAG Investigators. A pharmacogenetic versus a clinical algorithm for warfarin dosing. N Engl J Med. 2013 Dec 12;369(24):2283-93.

35. Jones M, McEwan P, Morgan CL, Peters JR, Goodfellow J, Currie CJ. Evaluation of the pattern of treatment, level of anticoagulation control, and outcome of treatment with warfarin in patients with non-valvar atrial fibrillation: a record linkage study in a large British population. Heart. 2005 Apr;91(4):472-7.

36. Van Spall HG, Wallentin L, Yusuf S, Eikelboom JW, Nieuwlaat R, Yang S, Kabali C, Reilly PA, Ezekowitz MD, Connolly SJ. Variation in warfarin dose adjustment practice is responsible for differences in the quality of anticoagulation control between centers and countries: an analysis of patients receiving warfarin in the randomized evaluation of longterm anticoagulation therapy (RE-LY) trial. Circulation. 2012 Nov 6;126(19):2309-16.

37. Verhoef TI, Redekop WK, Darba J, Geitona M, Hughes DA, Siebert U, de Boer A, Maitland-van der Zee AH, Barallon R, Briz M, Daly A, Haschke-Becher E, Kamali F, Kirchheiner J, Manolopoulos VG, Pirmohamed M, Rosendaal FR, van Schie RM, 
Wadelius M; EU-PACT Group. A systematic review of cost-effectiveness analyses of pharmacogenetic-guided dosing in treatment with coumarin derivatives. Pharmacogenomics. $2010 \mathrm{Jul} ; 11(7): 989-1002$. (** an important systematic review on economic evaluation of pharmacogenetic-guided dosing of warfarin)

38. Verhoef TI, Redekop WK, Langenskiold S, Kamali F, Wadelius M, Burnside G, Maitlandvan der Zee AH, Hughes DA, Pirmohamed M. Cost-effectiveness of pharmacogeneticguided dosing of warfarin in the United Kingdom and Sweden. Pharmacogenomics J. 2016 Oct;16(5):478-84.

39. Ghadimi K, Dombrowski KE, Levy JH, Welsby IJ. Andexanet alfa for the reversal of Factor Xa inhibitor related anticoagulation. Expert Rev Hematol. 2016;9(2):115-22.

40. Damaske DL, Baird RW. Development and implementation of a pharmacist-managed inpatient warfarin protocol. Proc (Bayl Univ Med Cent). 2005 Oct;18(4):397-400.

41. Saokaew S, Sapoo U, Nathisuwan S, Chaiyakunapruk N, Permsuwan U. Anticoagulation control of pharmacist-managed collaborative care versus usual care in Thailand. Int $\mathrm{J}$ Clin Pharm. 2012 Feb;34(1):105-12.

42. Saokaew S, Permsuwan U, Chaiyakunapruk N, Nathisuwan S, Sukonthasarn A. Effectiveness of pharmacist-participated warfarin therapy management: a systematic review and meta-analysis. J Thromb Haemost. 2010 Nov;8(11):2418-27.

43. Lee YP, Schommer JC. Effect of a pharmacist-managed anticoagulation clinic on warfarin-related hospital readmissions. Am J Health Syst Pharm. 1996 Jul 1;53(13):1580-3.

44. Mattaya S, Anusornsangiam W, Kanjanasilp J, Klangsang J. Outcome of pharmaceutical care in anticoagulation clinic at Roi-Et hospital, Roi-Et province, Northeastern Thailand. J Sci Technol MSU 2008;27(1):59-67.

45. Biscup-Horn PJ, Streiff MB, Ulbrich TR, Nesbit TW, Shermock KM. Impact of an inpatient anticoagulation management service on clinical outcomes. Ann Pharmacother. 2008 Jun;42(6):777-82.

46. Munjamroon $Y$, Suttajit S, Tammarat T, Saritreechaikun D. Clinical outcomes of warfarin monitoring in outpatients at Nakorn Phanom Hospiatal. J Sci Technol MSU 2007;26:3846.

47. Zed PJ, Filiatrault L. Clinical outcomes and patient satisfaction of a pharmacist-managed, emergency department-based outpatient treatment program for venous thromboembolic disease. CJEM. 2008 Jan;10(1):10-7.

48. Krittathanmakul S, Silapachote $P$, Pongwecharak J, Wongsatit U. Effects of pharmacist counseling on outpatients receiving warfarin at Songklanagarind Hospital. Songkla Med J 2006;24(2):93-9. 
49. Macik BG. The future of anticoagulation clinics. J Thromb Thrombolysis. 2003 AugOct;16(1-2):55-9.

50. Schalekamp T, de Boer A. Pharmacogenetics of oral anticoagulant therapy. Curr Pharm Des. 2010;16(2):187-203.

51. Wadelius M, Chen LY, Lindh JD, Eriksson N, Ghori MJ, Bumpstead S, Holm L, McGinnis $R$, Rane A, Deloukas P. The largest prospective warfarin-treated cohort supports genetic forecasting. Blood. 2009 Jan 22;113(4):784-92.

52. Sconce EA, Khan TI, Wynne HA, Avery P, Monkhouse L, King BP, Wood P, Kesteven P, Daly AK, Kamali F. The impact of CYP2C9 and VKORC1 genetic polymorphism and patient characteristics upon warfarin dose requirements: proposal for a new dosing regimen. Blood. 2005 Oct 1;106(7):2329-33.

53. Bodin L, Verstuyft C, Tregouet DA, Robert A, Dubert L, Funck-Brentano C, Jaillon P, Beaune P, Laurent-Puig P, Becquemont L, Loriot MA. Cytochrome P450 2C9 (CYP2C9) and vitamin $\mathrm{K}$ epoxide reductase (VKORC1) genotypes as determinants of acenocoumarol sensitivity. Blood. 2005 Jul 1;106(1):135-40.

54. Schalekamp T, Brassé BP, Roijers JF, van Meegen E, van der Meer FJ, van Wijk EM, Egberts AC, de Boer A. VKORC1 and CYP2C9 genotypes and phenprocoumon anticoagulation status: interaction between both genotypes affects dose requirement. Clin Pharmacol Ther. 2007 Feb;81(2):185-93.

55. Aithal GP, Day CP, Kesteven PJ, Daly AK. Association of polymorphisms in the cytochrome P450 CYP2C9 with warfarin dose requirement and risk of bleeding complications. Lancet. 1999 Feb 27;353(9154):717-9.

56. D'Andrea G, D'Ambrosio RL, Di Perna P, Chetta M, Santacroce R, Brancaccio V, Grandone E, Margaglione M. A polymorphism in the VKORC1 gene is associated with an interindividual variability in the dose-anticoagulant effect of warfarin. Blood. 2005 Jan 15;105(2):645-9.

57. International Warfarin Pharmacogenetics Consortium, Klein TE, Altman RB, Eriksson N, Gage BF, Kimmel SE, Lee MT, Limdi NA, Page D, Roden DM, Wagner MJ, Caldwell MD, Johnson JA. Estimation of the warfarin dose with clinical and pharmacogenetic data. $\mathrm{N}$ Engl J Med. 2009 Feb 19;360(8):753-64.

58. Lenzini $P$, Wadelius $M$, Kimmel S, Anderson JL, Jorgensen AL, Pirmohamed M, Caldwell MD, Limdi N, Burmester JK, Dowd MB, Angchaisuksiri P, Bass AR, Chen J, Eriksson N, Rane A, Lindh JD, Carlquist JF, Horne BD, Grice G, Milligan PE, Eby C, Shin J, Kim H, Kurnik D, Stein CM, McMillin G, Pendleton RC, Berg RL, Deloukas P, Gage BF. Integration of genetic, clinical, and INR data to refine warfarin dosing. Clin Pharmacol Ther. 2010 May;87(5):572-8. 